\title{
Biological Therapies or Apremilast in the Treatment of Psoriasis in Patients with a History of Hematologic Malignancy: Results from a Retrospective Study in 21 Patients
}

\author{
Raphaella Cohen-Sors' \\ Anne- \\ Claire Fougerousse $\mathbb{D D}^{2}$ \\ Ziad Reguiai ${ }^{3}$ \\ Francois Maccari ${ }^{2}$ \\ Emmanuel Mahé (1D ${ }^{4}$ \\ Juliette Delaunay ${ }^{5}$ \\ Aude Roussel ${ }^{2}$ \\ Maud Amy de la Breteque ${ }^{4}$ \\ Caroline Cottencin ${ }^{6}$ \\ Antoine Bertolotti ${ }^{7}$ \\ Hélène Kemp ${ }^{8}$ \\ Guillaume Chaby' \\ 'Dermatology Department, Amiens- \\ Picardie University Hospital Center, \\ Amiens, France; ${ }^{2}$ Dermatology \\ Department, Military Teaching Hospital \\ Bégin, Saint-Mandé, France; \\ ${ }^{3}$ Dermatology Department, Polyclinic \\ Courlancy, Reims, France; ${ }^{4}$ Dermatology \\ Department, Argenteuil Hospital, \\ Argenteuil, France; ${ }^{5}$ Dermatology \\ Department, University Hospital, Angers, \\ France; ${ }^{6}$ Dermatology Department, \\ University Hospital, Lille, France; \\ ${ }^{7}$ Dermatology Department, University \\ Hospital, Saint-Pierre, lle de la Réunion, \\ France; ${ }^{8}$ Hematology Department, \\ Amiens-Picardie University Hospital \\ Center, Amiens, France
}

Correspondence: Guillaume Chaby Email chaby.guillaume@chu-amiens.fr
Background: Few studies addressing the safety and efficacy of biological therapy (BT) or apremilast (APR) in patients with psoriasis with a history of hematologic malignancy (HM) exist.

Aim: To describe the tolerance and efficacy of BT and APR in moderate-to-severe psoriasis in patients with a history of in-remission or evolving HM.

Methodology: A retrospective, multicenter chart review of the tolerance and efficacy of BT or APR in patients with moderate-to-severe psoriasis and a clinical history of in-remission or evolving HM.

Results: Twenty-one patients with severe psoriasis and a history of HM were included in France by the GEM Resopso study group. Of the 16 patients treated with one or more BT lines, none showed recurrence of their HM which was considered as stable or in remission, and only 2 patients showed an evolution of their HM which had been considered as stable at the beginning of treatment. In the 10 patients treated with APR, the HM of one patient who also received BT worsened. The 3 evolutions did not impact the treatment with BT or APR. Tolerance was very satisfactory, with a low occurrence of infections. Regarding efficacy, only one patient treated with APR did not achieve any notable clinical improvement.

Conclusion: Despite supportive data regarding tolerance, the heterogeneity of the analyzed population and limited available data, BT and APR should be used with caution in this patient population and investigations on larger cohorts should be conducted to further assess their tolerance in this patient population.

Keywords: biological therapies, apremilast, psoriasis, hematological malignancies

\section{Introduction}

Biological therapies (BT) are humanized proteins synthesized by genetic engineering. BT in psoriasis comprise anti-TNF $\alpha$ (adalimumab, etanercept, infliximab, certolizumab pegol) and anti-interleukins including ustekinumab (anti-IL-12/23), secukinumab and ixekizumab (anti- IL-17), brodalumab (anti-receptor of IL-17), guselkumab and risankizumab (anti-IL-23). ${ }^{1,2}$

$\mathrm{BT}$ are well tolerated in patients with psoriasis. The most commonly reported adverse effects (AEs) associated with BT were upper respiratory tract infections. ${ }^{3}$ Generally the incidence of severe AEs in psoriatic patients receiving anti-IL-12/23 
antibody or IL-17 inhibitors was reported to be lower than that of TNF-a inhibitors, although that of TNF- $\alpha$ inhibitors is still very low. 4

Apremilast (APR, phosphodiesterase inhibitor 4) is an immunomodulator marketed since 2015 in Europe. ${ }^{5,6}$ In vitro and in vivo studies showed that APR is efficient on PDE4 activity, inflammatory signal expression, and dermal psoriasiform signs. In patients with moderate-to-severe psoriasis, APR significantly reduced plasma levels of interleukin (IL)-17F, IL-17A, IL-22, and tumor necrosis factor- $\alpha$ as well as of cytokines. ${ }^{7,8}$ Overall, treatment with APR is safe. However, a few common ( $\geq 5 \%$ of patients) mild to moderate AEs have been reported, including diarrhea, nausea, headache, and nasopharyngitis. ${ }^{9}$

Patients with psoriasis have been reported to present with an increased risk of cancer, which may be due to impaired immune surveillance, immune modulatory treatments, chronic inflammation and/or co-risk factors such as obesity. BT are independently associated with a slight increase risk of cancer, but this is less than cyclosporine, with the risk confounded by disease severity and other corisk factors. The data on small molecule therapies such as APR are currently considered to be immature for comment, although no signal has yet been identified. ${ }^{10}$

In France, BT and apremilast APR are recommended as a treatment option in adults with moderate-to-severe psoriasis that has not responded to at least 2 standard systemic therapies, such as cyclosporine, methotrexate, or phototherapy; or in patients who are intolerant of, or have a contraindication to these treatments. ${ }^{11}$

The use of BT and APR is currently not contraindicated in patients with psoriasis and a history of hematological malignancies (HM). ${ }^{12}$ However, several recommendations encourage caution and propose to limit their use to severe psoriasis after consultation with a hematologist as part of an individual benefit/risk consideration. $^{13,14}$

The influence of BTs on the evolution of HM remains largely unknown. The evidence from basic research does not support the existence of a potentially deleterious effect of TNF $\alpha$ or interleukin inhibition on the evolution of blood disorders. ${ }^{15-20}$ Conversely, in some situations, treatments with anti-TNF alpha or anti-IL17 have been proposed for the treatment of different malignant hematologic diseases. ${ }^{21-24}$ The most substantiated clinical information from registries relates to the risk of relapse of TNF lymphoma during rheumatoid arthritis with reassuring conclusions. However, these findings are based on a small number of patients and a limited follow-up. ${ }^{25,26}$ Except for these data, there is no information available in the literature about the risk of recurrence or evolution of any malignant HM, and especially in indications other than RA, particularly in psoriasis. No treatment-related carcinogenic risk with APR has been identified in animal carcinogenicity studies. ${ }^{27}$ However, no current practice data are available to discuss its potential impact on patients with HM.

The purpose of this study was to describe the tolerance and efficacy of BT and APR in moderate-to-severe psoriasis in patients with a history of in-remission or evolving HM.

\section{Methodology}

This study was a national-wide, retrospective, multicenter observational chart review conducted in France in private practice or at hospital sites by the GEM Resopso study group. Resopso (http://resopso.fr) is an association of dermatologists throughout France involved in the care and research of patients with psoriasis. The research protocol was approved by the local research and innovation department (Direction de la Recherche Clinique et de l'Innovation CHU Amiens - ref: PI2020-843-0025). According to the French law JARDE (Décret no 20161537), patients had to provide a written non-opposal for using their data for this project. The study was conducted according to the principles of the declaration of Helsinki and conformed to local legal data protection requirements (CNIL, MR003).

Any adult patients receiving BT or APR for their moderate-to-severe psoriasis (ongoing or discontinued) and who had a clinical history of remission or of an evolving HM were suitable for the study. Data from patients with a history of monoclonal gammapathies of undetermined significance were not to be included.

The following data were collected: demographic, psoriasis severity before BT/APR, type of HM prior to BT/ APR, type of BT, efficacy of BT or APR on psoriasis, reported adverse events with BT or APR and evolution of $\mathrm{HM}$ during treatment with $\mathrm{BT}$ or APR.

Data about the HM stage according to its classification as well as its prognostic score, if indicated, were collected in order to assess its severity. For each type of HM, its status (in remission, stable or evolving before initiating BT or APR) was indicated.

Evolution was defined as a) in remission, if clinical and biological normalization; b) stable, if no worsening of the 
HM or no introduction of a new-treatment for HM and c) evolving, in case of worsening of the HM stage or exacerbation of HM (eg evolution into acute myeloid leukemia for myelodysplastic syndrome (MDS), or evolution into lymphoma for chronic lymphoid leukemia (CLL)) and/or in the event of a newly initiated treatment for HM and/or recurrence of $\mathrm{HM}$.

Tolerance was assessed according to the evolution of HM after treatment with BT or APR had started. Adverse events (infections or other events) that occurred during treatment with BT or APR were collected.

The efficacy of BT or APR was evaluated, based on the psoriasis severity score assessed during the last dermatology consultation using the psoriasis global assessment (PGA), body surface area (BSA), and psoriasis area severity index (PASI).

Descriptive statistics were performed for all parameters. For categorical variables, numbers and frequencies were calculated. For continuous numerical variables, averages, median, minimum, maximum and standard deviations were calculated.

\section{Results}

\section{Patient and Disease Data}

We analyzed data from 21 patients, 4 women and 17 men; the mean age was 63 , ranging from 50 to 82 years. Twenty (20) patients had plaque psoriasis, the remaining patient had palmoplantar pustular psoriasis.

Eighteen (18) patients had past first-line psoriasis treatments including phototherapy, acitretin, methotrexate and cyclosporine prior to BT or APR. In total, 24 treatment courses with BT (7 etanercept, 2 adalimumab, 2 infliximab, 7 ustekinumab, 4 secukinumab, 1 ixekizumab, 1 guselkumab) were identified in 16 patients; 10 patients received APR. Of those 10, 3 received APR prior to and 2 after treatment with BT, and 5 received only APR.

The median treatment duration with BT and APR was 16 months [3-120] and 6 months [2-30] respectively. Seven (7/21) patients had been on BT/APR treatment for less than one year and the majority of patients (14/21) had been on BT/APR treatment for more than 2 years at the last evaluation.

The delay between diagnosis of HM and initiation of BT or APR was on average 54 months, ranging from 0 to 240 months.

Detailed patient and disease information is provided in Table 1.

\section{Tolerance}

Detailed tolerance results for each of the 21 patients are provided in Table 2 .

Of the 9 patients considered in remission before BT/ APR, none had recurrence reported. Four (4) patients received $\mathrm{BT}, 4$ received $\mathrm{APR}$, and one received both. Only one patient was still receiving maintenance treatment (brentuximab for anaplastic large-cell stage IV T-lymphoma).

Eleven (11) patients had a stable HM at the time BT or BT/APR was started. HM had been stabilized in 8 patients. The other 3 patients observed an evolution of their HM during treatment with BT (2 patients) and APR (one patient). One of these patients had a multi-treated Vaquez polycythemia, stabilized under ruxolitinib. After 31 months of successive treatments with etanercept, APR and secukinumab, his Vaquez disease evolved into a severe secondary myelofibrosis grade 3, requiring the introduction of erythropoietin and multiple transfusions of globular caps. Because of the patient's transition to palliative care, and to maintain his comfort, secukinumab was maintained. The second patient, followed by essential thrombocythemia JAK2 +, under simple supervision before the introduction of treatment with BT, presented with an ischemic stroke at 9 months from the start of the treatment with etanercept, associated with thrombocytosis, which motivated the introduction of treatment with hydroxycarbamide. Treatment with etanercept was continued with no evolution of HM. Finally, the last patient had a stable CLL grade A for 4 years after successive treatments with etanercept then adalimumab. Ten (10) months after switching to APR, an evolution of CLL was observed leading to the introduction of a treatment with obinutuzumab and chlorambucil. APR was continued and then stopped, due to a lack of efficacy.

The patient with an HM evolving prior to the introduction of BT/APR was followed for a recurrent stage IV follicular B lymphoma along with a severe psoriasis outbreak. Two (2) months after the initiation of APR, the patient had received vinblastine and was waiting for treatment with CAR-T cells (gene therapy, manufactured from the patient's T lymphocytes).

Five (5) patients presented a total of 7 significant adverse events. Three (3) patients had infectious complications: 2 patients with one episode of herpes skin infection after 3 months of secukinumab treatment and 6 months of ustekinumab treatment, respectively (the latter 
Table I Patient Demographic and Disease Data

\begin{tabular}{|c|c|}
\hline \multirow{3}{*}{$\begin{array}{l}\text { Gender, } \mathbf{N}(\%) \\
\text { Women } \\
\text { Men }\end{array}$} & \\
\hline & $4(19)$ \\
\hline & $17(8 \mid)$ \\
\hline \multicolumn{2}{|l|}{ Age (years) } \\
\hline Median [min-max] & $63[50-82]$ \\
\hline \multicolumn{2}{|l|}{ Main psoriasis type, $\mathbf{N}(\%)$} \\
\hline Plaque type & $20(95)$ \\
\hline Palmoplantar Pustular & I (5) \\
\hline \multicolumn{2}{|l|}{ Severity score prior to treatment, Mean \pm SD } \\
\hline PASI & $16.6(8)$ \\
\hline PGA & $3,6(0,85)$ \\
\hline BSA & $29(15)$ \\
\hline Prior systemic treatment, $\mathbf{N}(\%)$ & $18(86)$ \\
\hline Phototherapy & II (52) \\
\hline Methotrexate & $13(6 \mid)$ \\
\hline Cyclosporine & $2(10)$ \\
\hline Acitretine & $12(57)$ \\
\hline Etretinate & I (5) \\
\hline \multicolumn{2}{|l|}{ BT type administered, $\mathbf{N}(\%)$} \\
\hline Etanercept & $7(33)$ \\
\hline Infliximab & $2(10)$ \\
\hline Adalimumab & $2(10)$ \\
\hline Ustekinumab & $7(33)$ \\
\hline Secukinumab & $4(19)$ \\
\hline Ixekizumab & I (5) \\
\hline Guselkumab & I (5) \\
\hline APR, No (\%) & $10(48)$ \\
\hline \multicolumn{2}{|l|}{ Type of malign HM, N (\%) } \\
\hline Non-Hodgkin's lymphoma & $5(24)$ \\
\hline Hodgkin's lymphoma & $4(19)$ \\
\hline Chronic lymphoid leukemia & $5(24)$ \\
\hline Multiple myeloma & I (5) \\
\hline Waldenström disease & I (5) \\
\hline Vaquez disease & $3(14)$ \\
\hline Essential thrombocythemia & $2(10)$ \\
\hline $\begin{array}{l}\text { Delay between diagnosis and start of PT/ } \\
\text { APR treatment, Median [min-max] } \\
\text { (months) }\end{array}$ & $53[0-204]$ \\
\hline
\end{tabular}

Abbreviations: APR, apremilast; BT, biological treatment; HM, hematological malignancy; PASI, psoriasis area severity index; PGA, psoriasis global assessment; BSA, body surface area.

patient had been treated for more than 2 years with several successive BTs). The third patient presented with an acute prostatitis and secondary bilateral broncho-pneumopathy, which occurred more than 10 years after the start of his etanercept treatment and which led to its temporary suspension. One patient had multiple squamous cell carcinomas treated with surgery, 4 years after the onset of BT. This patient had previously received treatment with multiple sessions of phototherapy, prior to the onset of BT.

Two (2) patients had a stroke after taking etanercept for 9 months and more than 10 years after treatment had started; treatment was maintained (Table 2).

\section{Efficacy}

Mean psoriasis severity scores were evaluated during the last treatment received (BT or APR) for psoriasis. The PASI, PGA and BSA average scores at introduction of BT or APR were 16.6, 3.6 and $29 \%$ respectively. Improvement was significant in almost all patients (20/ 21) with average scores at the end of follow-up of 2.2 , 0.9 and $2.6 \%$. Eighteen (18) of the 21 patients had a PGA $0 / 1$ of which 6 had their psoriasis cured. Only one patient had not shown a marked improvement during treatment of more than 2 years of APR, with a PGA score of 4 to 3 at the end of the follow-up.

\section{Discussion}

This study analyzed data from 21 patients with severe psoriasis, who had a history of HM and were treated with BT or APR. Of the 16 patients treated with one or more BT lines, none showed recurrence and only 2 patients had an evolving HM. The HM of one patient who received APR and BT worsened. However, none of these 3 relapses impacted treatment with BT or APR. Tolerance was very satisfactory, as shown through the low occurrence of infectious episodes. Regarding efficacy, only one patient treated with APR did not achieve any notable clinical improvement.

To our knowledge, this is the most important series of cases of patients with a history of HM treated with BT for psoriasis. Furthermore, to date, no studies have evaluated the tolerance of APR regardless of the indication, in cases of a history of hematologic malignancy. Only Kahn et al, in 2019, reported results for patients treated with BT or APR for psoriasis with a history of cancer. ${ }^{28}$ In total, of the 16 patients with a history of cancer out of 690 patients in the cohort, only one patient had a history of hematologic malignancy and with no recurrence after a treatment lasting 23 months.

In the majority of our patients, HM did not recur or remained stable during treatment with BT or APR. Nevertheless, 3 patients observed an evolution of their HM. Two (2) cases of evolution observed with BT were reported 


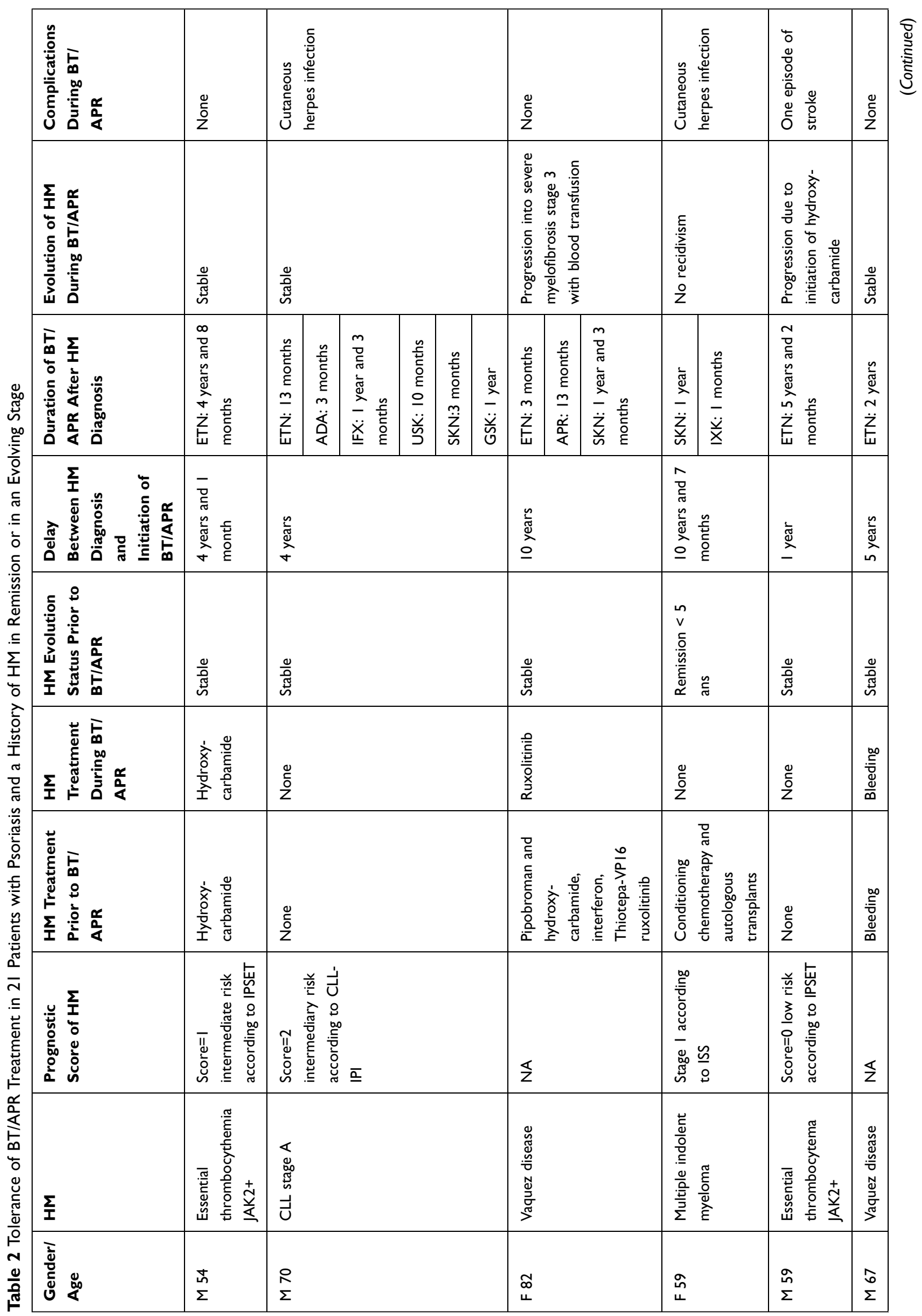




\begin{tabular}{|c|c|c|c|c|c|c|}
\hline 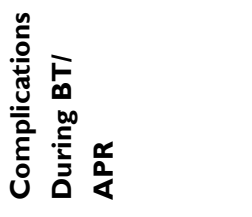 & 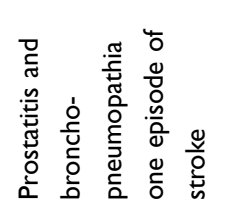 & $\begin{array}{l}\stackrel{0}{0} \\
\text { ż }\end{array}$ & $\begin{array}{l}\frac{0}{0} \\
\text { ż }\end{array}$ & $\begin{array}{l}\stackrel{0}{0} \\
\text { ż }\end{array}$ & $\begin{array}{l}0 \\
\frac{0}{0} \\
z\end{array}$ & $\begin{array}{l}\stackrel{0}{\bar{g}} \\
\stackrel{\bar{g}}{Z}\end{array}$ \\
\hline 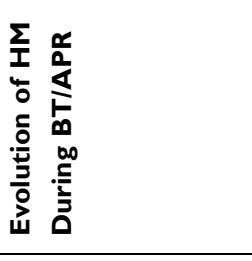 & 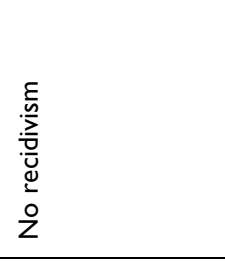 & 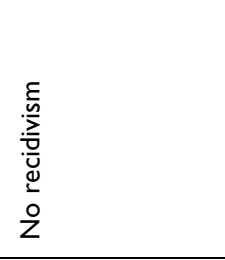 & $\begin{array}{l}\frac{0}{20} \\
\frac{5}{5}\end{array}$ & 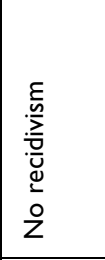 & 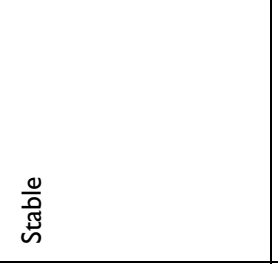 & 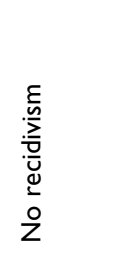 \\
\hline 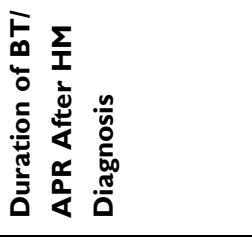 & 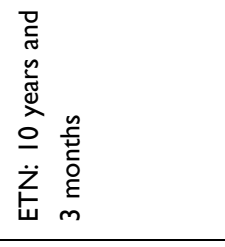 & 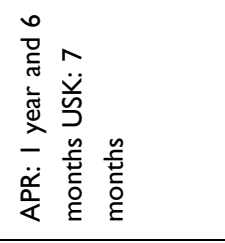 & 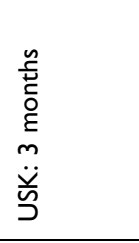 & 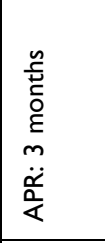 & 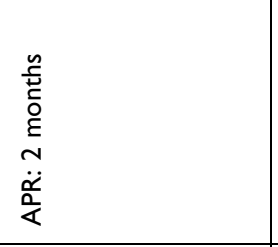 & 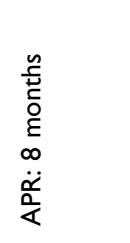 \\
\hline 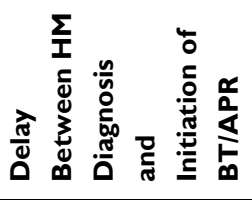 & $\begin{array}{l}\stackrel{n}{\tilde{E}} \\
\stackrel{\sim}{\sim}\end{array}$ & 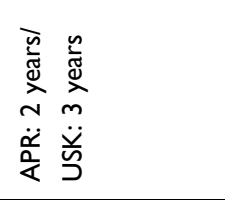 & 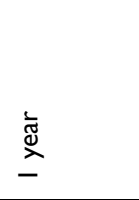 & 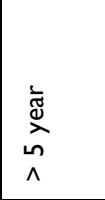 & $\begin{array}{l}\stackrel{n}{\mathbb{N}} \\
\stackrel{N}{\wedge}\end{array}$ & 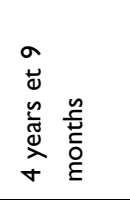 \\
\hline 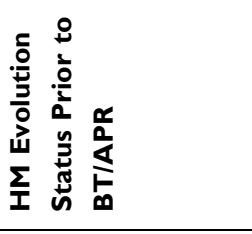 & 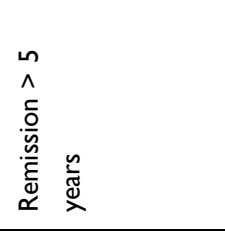 & 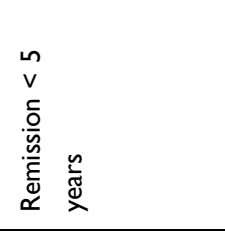 & $\begin{array}{l}\frac{0}{0} \\
\text { 胥 } \\
\end{array}$ & 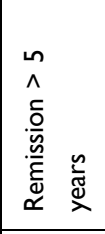 & 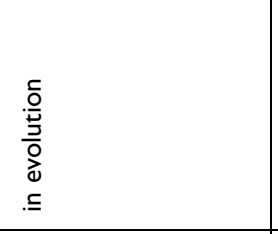 & 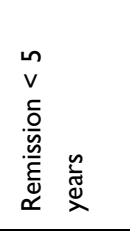 \\
\hline 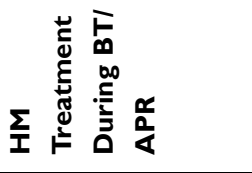 & $\frac{\stackrel{0}{0}}{\frac{0}{z}}$ & 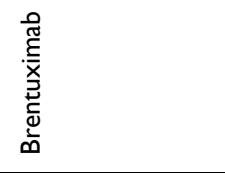 & $\frac{\stackrel{0}{0}}{\frac{0}{2}}$ & $\begin{array}{l}\stackrel{0}{0} \\
\text { ż }\end{array}$ & 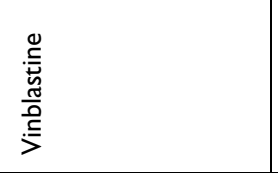 & $\frac{0}{\tilde{0}}$ \\
\hline 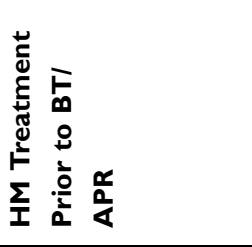 & 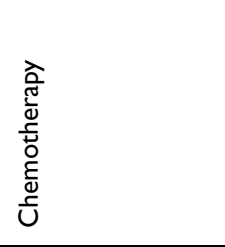 & 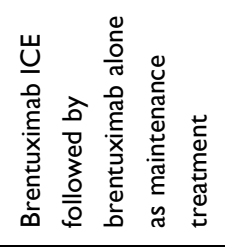 & $\begin{array}{l}\stackrel{0}{5} \\
\stackrel{5}{z}\end{array}$ & 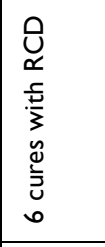 & 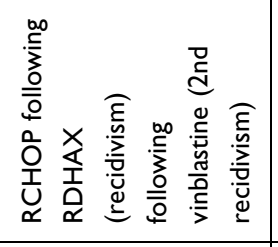 & 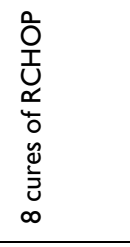 \\
\hline 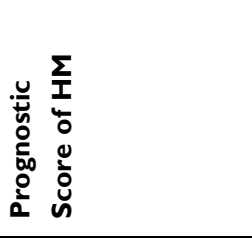 & $\frac{\alpha}{z}$ & 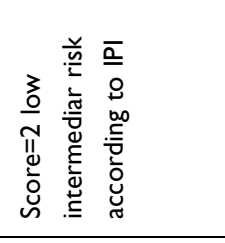 & 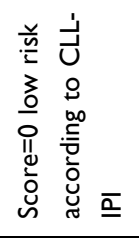 & 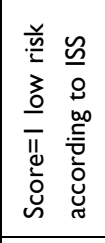 & 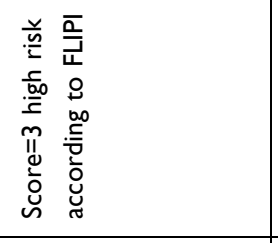 & 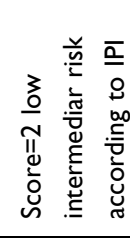 \\
\hline$\sum_{I}$ & 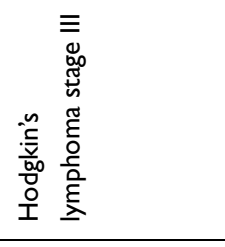 & 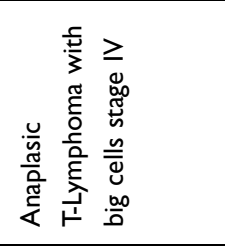 & 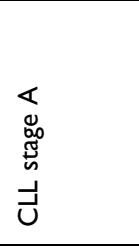 & 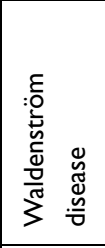 & 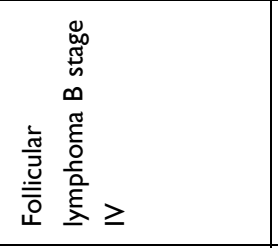 & 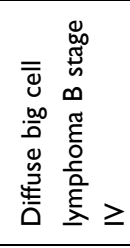 \\
\hline 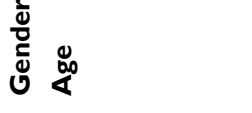 & $\stackrel{\infty}{\Sigma}$ & $\underset{\Sigma}{\tilde{\Sigma}}$ & 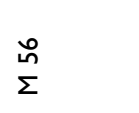 & $\stackrel{\mathscr{0}}{\Sigma}$ & $\begin{array}{l}\pi \\
\dot{u}\end{array}$ & $\stackrel{\tilde{N}}{\Sigma}$ \\
\hline
\end{tabular}




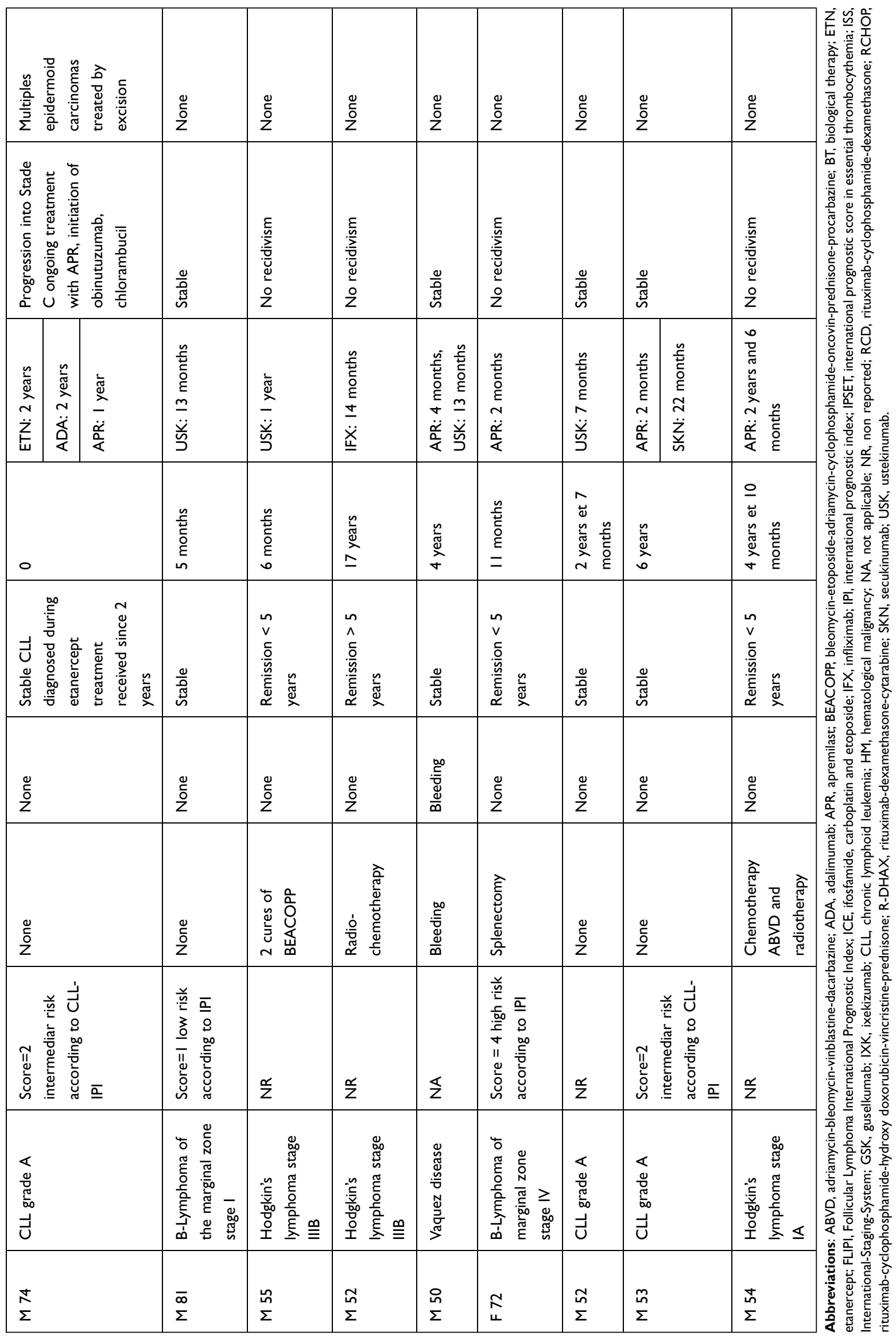


for one patient with a Vaquez polycythemia, and for one patient with a JAK2+ essential thrombocythemia. The patient with Vaquez's polycythemia was followed for more than 10 years during the transformation into myelofibrosis. However, as Vaquez polycythemia or an essential thrombocythemia may progress into secondary myelofibrosis in about $10 \%$ of cases after 10 years of follow-up depending on the studies, BT might not be considered to be responsible for the evolution. ${ }^{29}$ The second patient had an essential thrombocythemia that worsened following a stroke 9 months after the introduction of etanercept. The stroke was considered a progressive sign of hematology caused by the introduction of hydroxycarbamide. However, this interpretation can be weighted by the fact that thrombocythemia was not treated at the time of the introduction of BT and that platelet counts remained stable during the first months of BT treatment prior to introduction of hydroxycarbamide.

Evolution when taking APR was observed in one patient with a grade A CLL. The evolution of the disease to highstage CLL led to the introduction of obinutuzumab and chlorambucil. As the risk of evolution from stage A to stage $\mathrm{B}$ or $\mathrm{C}$, regardless of treatment with $\mathrm{BT}$ or APR is $50 \%$, treatment with APR was considered not to be responsible for the evolution by the hematologists. ${ }^{30}$ APR was continued and then stopped, due to lack of efficacy.

Despite an increased risk of infection in patients with HM, and particularly when considered active, BT treatment tolerance was acceptable in 16-patient series after a median treatment duration of 16 months. Two patients had herpes skin infection, a well-known adverse effect in patients treated with BT outside of any history of cancer or hematology. Another patient presented successively with acute prostatitis and pneumopathy under etanercept, which evolved favorably after a transient cessation of BT. No opportunistic or mycobacterial infections, and no serious sepsis were reported. Furthermore, no infectious complications were observed in patients who received APR. This favorable result of APR is consistent with tolerance results of the Phase III studies, which note the absence of a significant difference with placebo regarding the occurrence of infections, since these events are also considered exceptional and of low severity. ${ }^{18}$

The efficacy of BT and APR was very satisfactory in patients with severe psoriasis that was not controlled by one or more conventional systemic treatment lines. This point is important to underline because these cases are difficult to manage due to their malignant hematology, excluding certain immunosuppressants usually used in severe psoriasis.
Despite the encouraging results, our data analysis has certain limitations. The main limit of our study is the lack of data that would have possibly allowed a comparison reflecting a rare prescription circumstance, whether in the field of Dermatology, Rheumatology or Gastroenterology. Our workforce remains relatively small despite the involvement of the multi-center RESOPSO group. It is also likely that the low numbers are related to the reluctance of prescribers who suffer from a lack of clear recommendations when BT is indicated in patients with a history of HM. The majority of patients had a confirmed history of HM with a status considered to be in remission or stable, and therefore results cannot be generalized to HM with a less favorable prognosis. Furthermore, one third of the patients received $\mathrm{BT}$ or APR for less than one year at the time of inclusion. We agree that a longer follow-up of these patients would have been preferable in order to confirm the good tolerance and efficacy of the treatments.

In conclusion, despite the present supportive tolerance data, the heterogeneity of our population and the limited available data, BT and APR should be used with caution in this patient population and investigations on larger cohorts should be conducted in order to further assess its tolerance in this type of patient with HM.

\section{Abbreviations}

APR, Apremilast; BSA, Body surface area; BSRBR, British Society of Rheumatology Biologics Register; BT, Biological therapy; CLL, Chronic lymphoid leukemia; HM, Hematological malignancies; MDS, Myelodysplastic syndrome; PASI, Psoriasis area severity index; PGA, Psoriasis global assessment; TNF, Tumor necrosis factor.

\section{Acknowledgments}

The authors acknowledge the members of the Groupe d'études multicentrique GEM RESOPSO for their participation and Karl Patrick Göritz, SMWS, Scientific and Medical Writing Services, France for writing assistance.

\section{Funding}

There is no funding to report.

\section{Disclosure}

Dr Ziad Reguiai is the board, investigator, speaker for Novartis, Janssen-Cilag, Lilly, eo-Pharma, Celgene, Pfizer, $\mathrm{UCB}$, Amgen, Almirall, MSD, and MEDAC, during the conduct of the study. Dr Emmanuel Mahé reports personal fees from AbbVie, Novartis, Lilly, Leo Pharma, Celgene, and 
Amgen, during the conduct of the study. Dr Juliette Delaunay reports personal fees from AbbVie, Novartis, Janssen, Leo Pharma, and Lilly, during the conduct of the study. The authors report no other conflicts of interest in this work.

\section{References}

1. Chen YC, Huang YT, Yang CC, et al. Real-world efficacy of biological agents in moderate-to-severe plaque psoriasis: an analysis of 75 patients in Taiwan. PLoS One. 2020;15(12):e0244620. doi:10.1371/ journal.pone. 0244620

2. Sbidian E, Chaimani A, Garcia-Doval I, et al. Systemic pharmacological treatments for chronic plaque psoriasis: a network meta-analysis. Cochrane Database Syst Rev. 2017;12(12): Cd011535. doi:10.1002/14651858.CD011535.pub2

3. Crowley JJ, Warren RB, Cather JC. Safety of selective IL-23p19 inhibitors for the treatment of psoriasis. J Eur Acad Dermatol Venereol. 2019;33(9):1676-1684. doi:10.1111/jdv.15653

4. Kamata M, Tada Y. Safety of biologics in psoriasis. J Dermatol. 2018;45(3):279-286. doi:10.1111/1346-8138.14096

5. Keating GM. Apremilast: a review in psoriasis and psoriatic arthritis. Drugs. 2017;77(4):459-472. doi:10.1007/s40265-017-0709-1

6. Schafer PH, Parton A, Capone L, et al. Apremilast is a selective PDE4 inhibitor with regulatory effects on innate immunity. Cell Signal. 2014;26(9):2016-2029. doi:10.1016/j.cellsig.2014.05.014

7. Pincelli C, Schafer PH, French LE, Augustin M, Krueger JG. Mechanisms underlying the clinical effects of apremilast for psoriasis. J Drugs Dermatol. 2018;17(8):835-840.

8. Schafer P. Apremilast mechanism of action and application to psoriasis and psoriatic arthritis. Biochem Pharmacol. 2012;83 (12):1583-1590. doi:10.1016/j.bcp.2012.01.001

9. Langley A, Beecker J. Management of common side effects of apremilast. J Cutan Med Surg. 2018;22(4):415-421. doi:10.1177/ 1203475417748886

10. Rademaker M, Rubel DM, Agnew K, et al. Psoriasis and cancer. An Australian/New Zealand narrative. Australas J Dermatol. 2019;60 (1):12-18. doi:10.1111/ajd.12889

11. Rønholt K, Iversen L. Old and new biological therapies for psoriasis. Int J Mol Sci. 2017;18(11):2297. doi:10.3390/ijms18112297

12. Armstrong AW, Puig L, Joshi A, et al. Comparison of biologics and oral treatments for plaque psoriasis: a meta-analysis. JAMA Dermatol. 2020;156(3):258-269. doi:10.1001/jamadermatol. 2019.4029

13. Rich P, Gooderham M, Bachelez H, et al. Apremilast, an oral phosphodiesterase 4 inhibitor, in patients with difficult-to-treat nail and scalp psoriasis: results of 2 phase III randomized, controlled trials (ESTEEM 1 and ESTEEM 2). J Am Acad Dermatol. 2016;74 (1):134-142. doi:10.1016/j.jaad.2015.09.001

14. Bissonnette R, Pariser DM, Wasel NR, et al. Apremilast, an oral phosphodiesterase-4 inhibitor, in the treatment of palmoplantar psoriasis: results of a pooled analysis from phase II PSOR-005 and phase III Efficacy and Safety Trial Evaluating the Effects of Apremilast in Psoriasis (ESTEEM) clinical trials in patients with moderate to severe psoriasis. J Am Acad Dermatol. 2016;75(1):99-105. doi:10.1016/j.jaad.2016.02.1164

15. Fiorentino D, Ho V, Lebwohl MG, et al. Risk of malignancy with systemic psoriasis treatment in the psoriasis longitudinal assessment registry. J Am Acad Dermatol. 2017;77(5):845-54.e5. doi:10.1016/j. jaad.2017.07.013

16. Peleva E, Exton LS, Kelley K, Kleyn CE, Mason KJ, Smith CH. Risk of cancer in patients with psoriasis on biological therapies: a systematic review. $B r \quad J$ Dermatol. 2018;178(1):103-113. doi:10.1111/bjd.15830
17. Garcia-Doval I, Descalzo MA, Mason KJ, et al. Cumulative exposure to biological therapy and risk of cancer in patients with psoriasis: a meta-analysis of Psonet studies from Israel, Italy, Spain, the U.K. and Republic of Ireland. Br J Dermatol. 2018;179(4):863-871. doi:10.1111/ bjd. 16715

18. Crowley J, Thaçi D, Joly P, et al. Long-term safety and tolerability of apremilast in patients with psoriasis: pooled safety analysis for $\geq 156$ weeks from 2 phase 3, randomized, controlled trials (ESTEEM 1 and 2). J Am Acad Dermatol. 2017;77(2):310-7.e1. doi:10.1016/j. jaad.2017.01.052

19. Askling J, Fahrbach K, Nordstrom B, Ross S, Schmid CH, Symmons D. Cancer risk with tumor necrosis factor alpha (TNF) inhibitors: meta-analysis of randomized controlled trials of adalimumab, etanercept, and infliximab using patient level data. Pharmacoepidemiol Drug Saf. 2011;20(2):119-130. doi:10.1002/pds.2046

20. Burmester GR, Mease P, Dijkmans BA, et al. Adalimumab safety and mortality rates from global clinical trials of six immune-mediated inflammatory diseases. Ann Rheum Dis. 2009;68(12):1863-1869. doi:10.1136/ard.2008.102103

21. Freedman JD, Gottlieb AB, Lizzul PF. Physician performance measurement: tiered networks and dermatology (an opportunity and a challenge). J Am Acad Dermatol. 2011;64(6):1164-1169. doi:10.1016/j.jaad.2010.07.004

22. Mariette X, Matucci-Cerinic M, Pavelka K, et al. Malignancies associated with tumour necrosis factor inhibitors in registries and prospective observational studies: a systematic review and meta-analysis. Ann Rheum Dis. 2011;70(11):1895-1904. doi:10.1136/ard.2010.149419

23. Wolfe F, Michaud K. Biologic treatment of rheumatoid arthritis and the risk of malignancy: analyses from a large US observational study. Arthritis Rheum. 2007;56(9):2886-2895. doi:10.1002/art.22864

24. Askling J, Fored CM, Brandt L, et al. Risks of solid cancers in patients with rheumatoid arthritis and after treatment with tumour necrosis factor antagonists. Ann Rheum Dis. 2005;64(10):1421-1426. doi:10.1136/ard.2004.033993

25. Leombruno JP, Einarson TR, Keystone EC. The safety of anti-tumour necrosis factor treatments in rheumatoid arthritis: meta and exposure-adjusted pooled analyses of serious adverse events. Ann Rheum Dis. 2009;68(7):1136-1145. doi:10.1136/ard.2008.091025

26. LE BLAY P, Mouterde G, Barnetche T, Morel J, Combe B. Shortterm risk of total malignancy and nonmelanoma skin cancers with certolizumab and golimumab in patients with rheumatoid arthritis: metaanalysis of randomized controlled trials. J Rheumatol. 2012;39 (4):712-715. doi:10.3899/jrheum.110982

27. Dommasch ED, Abuabara K, Shin DB, Nguyen J, Troxel AB, Gelfand JM. The risk of infection and malignancy with tumor necrosis factor antagonists in adults with psoriatic disease: a systematic review and meta-analysis of randomized controlled trials. J Am Acad Dermatol. 2011;64(6):1035-1050. doi:10.1016/j.jaad.2010.09.734

28. Kahn JS, Casseres RG, Her MJ, Dumont N, Gottlieb AB, Rosmarin D. Treatment of psoriasis with biologics and apremilast in patients with a history of malignancy: a retrospective chart review. J Drugs Dermatol. 2019;18(4):S1545961619P0387X.

29. Björkholm M, Hultcrantz M, Derolf ÅR. Leukemic transformation in myeloproliferative neoplasms: therapy-related or unrelated? Best Pract Res Clin Haematol. 2014;27(2):141-153. doi:10.1016/j. beha.2014.07.003

30. Jacque N, Leblond V. [Chronic lymphocytic leukemia]. Presse Med. 2019;48(7-8 Pt 1):807-815. Norwegian. doi:10.1016/j. 1pm.2019.07.019 


\section{Publish your work in this journal}

Clinical, Cosmetic and Investigational Dermatology is an international, peer-reviewed, open access, online journal that focuses on the latest clinical and experimental research in all aspects of skin disease and cosmetic interventions. This journal is indexed on CAS.
The manuscript management system is completely online and includes a very quick and fair peer-review system, which is all easy to use. Visit http://www.dovepress.com/testimonials.php to read real quotes from published authors. 